\title{
A transformação na paisagem causada pela atividade mineradora na Serra da Monguba/CE
}

The transformation in the landscape caused by mining activity in Sierra Monguba/CE

BANDEIRA $^{1}$, T. V.; OLIVEIRA ${ }^{2}$, Í. P.

tulioviana18@gmail.com;

\begin{abstract}
Resumo
O presente trabalho tem como objetivo discutir as modificações na paisagem ocasionadas pela atividade mineradora na localidade de Monguba. Para entender a problemática em questão, torna-se essencial conhecer a diversidade de elementos constituintes em sua paisagem, uma vez que, são eles os responsáveis pela formação de sua dinâmica juntamente com as ações socioeconômicas. Diante isso, foi aplicada a teoria geossistêmica proposta por Bertrand para compreender a inter-relação existente nos componentes que formam a área de estudo. Com isso, foram obtidos alguns resultados, tais como: a caracterização ambiental da área e a modificação de seu equilíbrio causado pela degradação ambiental advinda da pedreira. Esse trabalho se configura de grande importância, pois discussões são levantadas a respeito dos processos de transformação da paisagem e de que forma eles podem impactar no ambiente e na sociedade.
\end{abstract}

Palavras-chave: Degradação Ambiental, Atividade Mineradora e Geossistema.

\begin{abstract}
This study aims to address about the landscape changes caused by mining activity in Monguba location. To understand the problem in question, it is essential to know the diversity of the constituent elements in your landscape, since they are responsible for the formation of their dynamics with socioeconomic actions. Before it was applied to geosystemic theory proposed by Bertrand (1972) to understand the interrelationship of the components that make up the landscape of the study area. Thus, we obtained some results, such as the environmental characterization of the area and the modification of its balance caused by environmental degradation arising from the quarry. This work is configured of great importance, because discussions are raised about the landscape of transformation processes and how they may impact on the environment and society.
\end{abstract}

Keywords: Environment degradation, Mining Activity and Geosystem.

\section{INTRODUÇÃO}

A área de estudo (Figura 01), encontra-se localizada entre os municípios de Pacatuba e Maracanaú, esse tem sua formação histórica relacionada ao povoamento de núcleos em sesmarias próximos aos sopés do Maciço da Aratanha. Essas terras doadas pelos portugueses eram em geral férteis e, por isso, obteve um grande número de moradores culminando na criação de povoados. Em 18 de março de 1842, passou a ser distrito de Maranguape e em 8 de outubro de 1869 se torna vila. Mas, enquanto município, Pacatuba foi fundada em 17 de agosto de 1889. Já Maracanaú, torna-se distrito de Maranguape em 1906 e ganha autonomia em 1983, após três tentativas falhadas de emancipação. 

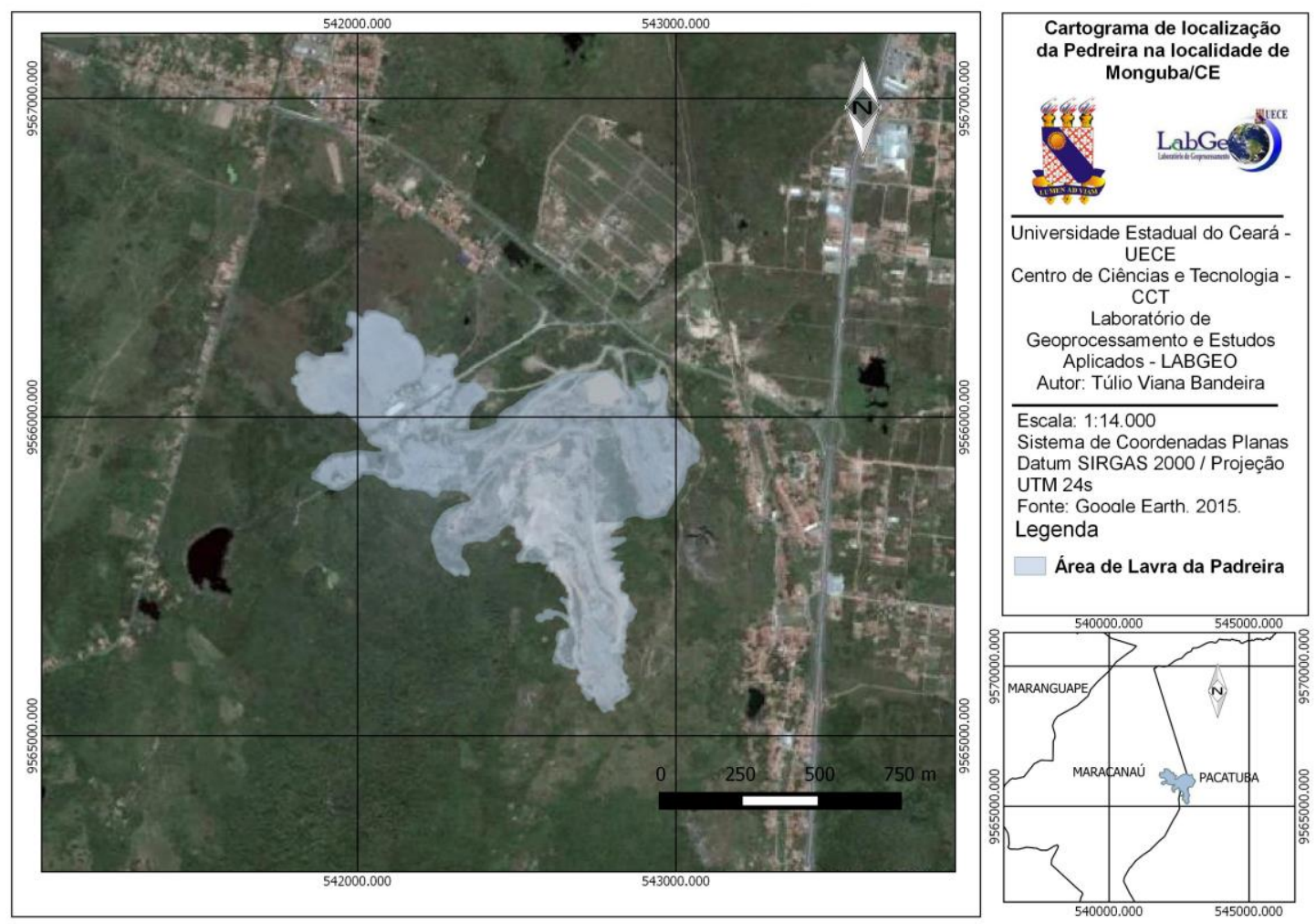

Figura 01. Cartograma de localização da Pedreira na localidade de Monguba/CE. Autor: BANDEIRA, 2016.

A localidade de Monguba criada no ano de 1989, situa-se próximo à Rodovia CE 060, estando sua área no sopé do Maciço da Aratanha a qual possui melhores condições ambientais e de recursos naturais em termos climáticos, pedológicos e hidrológicos do que a região no entorno (SOUZA; OLIVEIRA, 2006). O Maciço em questão, é formado por rochas graníticas e quartzíticas, onde há maior resistência dos granitos em relação às rochas xistosas propiciando o trabalho da erosão diferencial (SOUZA, 2007). Como consequência, são áreas privilegiadas para a atuação das atividades capitalistas, principalmente para as indústrias de agregados da construção civil, uma vez que, o próprio granito serve de matéria-prima para a produção da brita.

$\mathrm{Na}$ vertente mais úmida do Maciço da Aratanha, predominam solos profundos, espécies com porte arbóreo, vegetação perenifólia, drenagem perene e uma maior atuação do intemperismo químico. Na vertente seca há predominância de intemperismo físico, solos rasos, drenagem intermitente, vegetação de porte arbóreo arbustivo e semi-caducifólia. Na serra da Monguba, ocorre a predominância da Caatinga com extrato arbustivo a qual se encontra fortemente desmatado devido atividades com alto poder de degradação, sendo a mineração umas das práticas econômicas que mais deixam marcas na paisagem. Seus solos são, em geral, rasos e pedregosos com presença de afloramentos rochosos. A localidade de Monguba ainda está inserida na Bacia do Rio Cocó que nasce no Maciço da Aratanha 
apresentando comprimento de $50 \mathrm{~km}$ passando por Maracanaú, Itaitinga e por fim Fortaleza onde está localizada sua foz.

É importante salientar que para constatar o processo de degradação do ambiente e a dinâmica de seus componentes está sendo utilizada a teoria geossistêmica, a mesma foi desenvolvida por Sotchava (1960) dentro da geografia na escola russa. A qual se apresenta como resultado da combinação entre fatores geomorfológicos, climáticos e hidrológicos, correspondendo ao potencial ecológico. Posteriormente, o geossistema se relaciona com a exploração biológica e com as ações antrópicas mantendo uma dinâmica que influenciará na modificação da paisagem. Ao criar esse termo, Sotchava o deixou vago principalmente em relação à noção de escala e conteúdo. Recebendo diversas críticas por não apresentar claramente os critérios para classificação e subdivisão do Geossistema, tornando-se um conceito teórico de difícil aplicação prática na concepção de alguns pesquisadores.

É com Bertrand (1968) que a geografia se apropria definitivamente do geossistema. Ele demostra a paisagem de forma integrada, além de abordar os aspectos naturais é necessário se relacionar com as ações humanas. Segundo (BERTRAND, 1972, p. 01):

\footnotetext{
A paisagem não é a simples adição de elementos geográficos disparatados. É, em uma determinada porção do espaço, o resultado da combinação dinâmica, portanto instável, de elementos físicos, biológicos e antrópicos que, reagindo dialeticamente, uns sobre os outros, fazem da paisagem um conjunto único e indissociável, em perpétua evolução.
}

Com base nessa visão holística, sistêmica e integrada da paisagem, Bertrand (1972) propõe uma taxonomia das paisagens em função da escala e nas escalas têmporo-espaciais da geomorfologia. Segundo Lima (2013), ao oposto da metodologia proposta por Sotchava, Bertrand não subdivide o Geossistema, mas o coloca em uma escala de classificação da paisagem dividida em seis níveis taxonômicos separados em unidades de paisagens superiores e inferiores. Segmentando seus elementos entre potencial ecológico (clima, hidrologia e geomorfologia), exploração biológica (vegetação, solo e fauna) e ação antrópica, todos em constante movimento e agindo dialeticamente uns sob os outros.

Diante do exposto, o trabalho tem como objetivo discutir as modificações da paisagem ocasionadas pela atividade mineradora na localidade de Monguba, compreende-se que o mesmo é de notória importância para diagnosticar a conservação dos elementos pertencentes à paisagem do ambiente. Além dos fatores de preservação dessas áreas, a utilização racional dos 
seus recursos naturais são problemas atuais a qual atenção da sociedade se encontra neles evidenciados. Diante disso, é necessário estudar de forma integrada a natureza para o entendimento de suas conexões existentes com as ações antrópicas, pois possibilita conhecer melhor a problemática e chegar ao melhor entendimento da dinâmica existente no ambiente.

\section{METODOLOGIA}

Para a compreensão do sistema ambiental da área de estudo e a caracterização de sua paisagem é utilizada a teoria geossistêmica proposta por Bertrand (1972), a qual propõe entender a dinâmica da natureza a partir das relações existentes entre o potencial ecológico, a exploração biológica e as ações da sociedade (Figura 02). Para isso, é necessário estudar a paisagem de forma integrada, ou seja, incluir todos os fatores e processos que compõem seu sistema e destacar suas relações de interdependências. Diante disso, no estudo em questão ao ser aplicado a teoria geossistêmica permitirá abordar o estado de conservação do ambiente juntamente com a ação da atividade mineradora na descaracterização de sua paisagem.

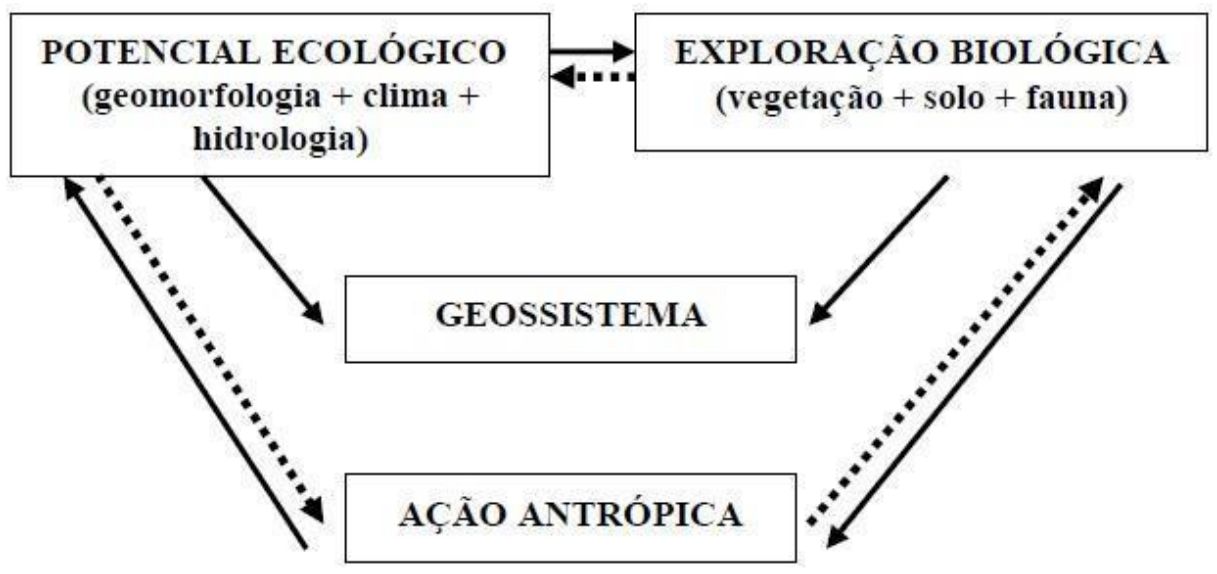

Figura 02. Esboço teórico apresentado por Bertrand (1972).

Além da utilização de autores, tais como: Guerra e Cunha (2006) com a finalidade de compreender as causas e as repercussões da degradação ambiental, Souza (2006 e 2007) também foi usado para identificar os elementos pertencentes à paisagem da área de estudo e Lima (2013) com a intenção de compreender as relações entre a teoria geossistêmica com a paisagem.

Através do levantamento literário realizado, foi possível enriquecer o presente trabalho, posteriormente os livros foram lidos e analisados para serem compreendidos e fazerem parte da obra. Outra parcela do material foi adquirido através da internet, na condição de artigos, monografias, livros on-line e o Plano de Manejo da Serra da Aratanha. Além disso, foi construída uma hemeroteca para uma análise temporal no que concerne a discussão. $\mathrm{O}$ 
trabalho de campo também foi realizado sendo imprescindível para investigar e analisar a dinâmica da paisagem, seus elementos e transformação. O mesmo serviu para ajudar na identificação do tipo de vegetação e de solo presente por meio dos registros fotográficos.

O mapa deste trabalho foi gerado através do software Quantum Gis utilizando uma escala grande para envolver uma menor área e aumentar o nível de detalhes. Foi empregada também uma imagem do Google Earth (2016) com o intuito de delimitar a área de estudo e para a confecção do mapa se utilizou o programa livre Quantum GIS.

\section{RESULTADOS E DISCUSSÃO}

A serra da Aratanha, onde está localizada a área de estudo, foi submetida no período quaternário a um tectonismo intenso que se caracteriza através de zonas fraturadas, dobradas e falhadas (SOUZA, 2007). O resultante dessas manifestações endógenas se revela em feições morfológicas escarpadas. De acordo com Souza e Oliveira (2006), as serras exibem uma dissecação pronunciada do relevo, derivada do forte aprofundamento proporcionado pela rede fluvial. Compõem um maciço sustentado por rochas graníticas e quartzíticas, onde os granitos são encontrados em maiores proporções que servem para a fabricação da brita e outros materiais de construção.

A Zona de Convergência Intertropical (ZCIT), é segundo Batista (2010) o principal sistema responsável pela maior parte das chuvas na Região Metropolitana de Fortaleza e no Ceará. Ela é formada por uma banda de nuvens que circunda a faixa equatorial do globo terrestre, originada principalmente pela confluência dos ventos alísios do hemisfério norte com os ventos alísios do hemisfério sul. Mas na maior parte do ano, o Ceará fica sob a ação do Anticiclone do Atlântico Sul, responsável pela estabilidade do tempo.

$\mathrm{Na}$ área de estudo há predominância do clima tropical quente sub-úmido e se apresenta entre o tipo climático Tropical quente úmido e Tropical quente semi-árido. Caracteriza-se por apresentar temperatura média sempre superior a $18^{\circ} \mathrm{C}$. O clima local juntamente com presença de umidade advinda do litoral e altitude do Maciço possibilita a fixação de algumas espécies de Mata Atlântica. Com o trabalho de campo, observou-se uma área de transição entre os biomas Caatinga e Mata Atlântica (Figura 03), onde são encontradas: Ziziphus joazeiro Mart. (juazeiro), Piptadenia communis (jurema-branca), Ceiba glaziovii (barriguda), Syagrus camosa (catolé), Croton sonderianus (marmeleiro) e Cnidoscolus urens (urtiga). O porte predominante é arbustivo-arbóreo e se apresenta bastante degradado na Serra da Monguba, onde, a retirada do granito e o desmatamento impõem modificações ao meio. Essa vegetação é de extrema importância para a proteção do solo local, além de aumentar sua capacidade de 
absorção de água e nutrir os organismos que ali vivem. Outra importância é a diminuição da temperatura devido à sombra criada por elas.

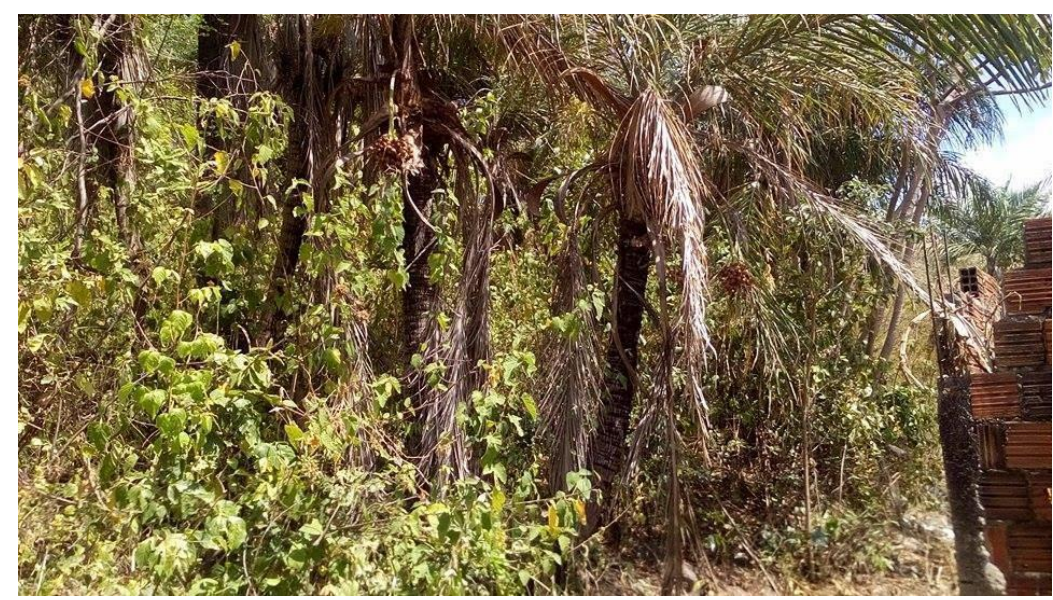

Figura 03. Vegetação da Serra da Monguba. Fonte: BANDEIRA, 2016.

A vegetação de caatinga da área de estudo ocupa a vertente mais úmida da Serra da Aratanha atingindo os níveis altimétricos mais baixos entre 300 - 400 metros, conforme Souza (2007) apesar de localizada na encosta a Sotavento, onde as condições permitem a fixação de uma vegetação Plúvio-nebular, os desmatamentos ocasionados pela mineração levam uma maior concentração da caatinga mais aberta e de menor porte em direção ao alto da Serra.

Em relação aos solos, associam-se aos Neossolos Litólicos e aos Argissolos vermelhoamarelos. Estes são dominantes por todo o maciço, ocupando principalmente o platô da Serra, sob condições de maior umidade. Segundo Souza (2007), eles são profundos, com textura argilosa e fertilidade natural de média a alta. Os Argissolos Vermelho Amarelos, possuem horizontes A, B e C, sendo o B um horizonte de acumulação de argila. São moderadamente bem drenados. Além das boas condições físicas, são indicadores de um bom potencial de uso.

Já os Neossolos Litólicos são comuns na área de estudo em áreas associadas aos afloramentos rochosos (Figura 04), com grande frequência nas posições mais desgastadas pela erosão. Eles são rasos, pedregosos e possuem baixa fertilidade natural. De acordo com a EMBRAPA (2006), os mesmos possuem fraca evolução pedogenética, apresentando perfis pouco desenvolvidos, possuindo somente o horizonte A sobreposto diretamente à rocha - R. Encontram-se desenvolvidos a partir de rochas cristalinas que ocupam o maciço. 


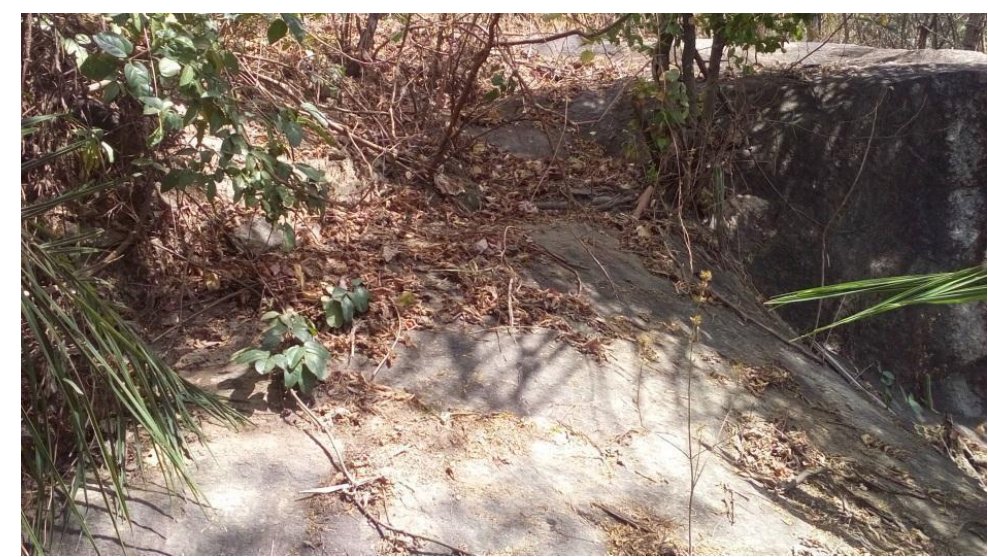

Figura 04. Solo raso e afloramentos rochosos. Fonte: BANDEIRA, 2016.

O solo e a vegetação local, além da população residente da área são os principais impactados pela atividade mineradora. Podendo-se notar a degradação ambiental em sua paisagem, uma vez que, segundo Guerra e Cunha (2006) esse processo é originado a partir das atividades socioeconômicas sobre a natureza tendo principalmente como causa o uso inadequado dos recursos naturais. A qual deve ser estudada de forma integrada com as questões sociais, pois o modo de vida atual se apresenta como fundamental a problemática. Na Serra da Monguba, essas questões podem ser vistas, pois algumas de suas encostas estão desprotegidas de vegetação (Figura 05) e como existe um forte contato do solo raso com a rocha, essas condições aceleram os processos de degradação.

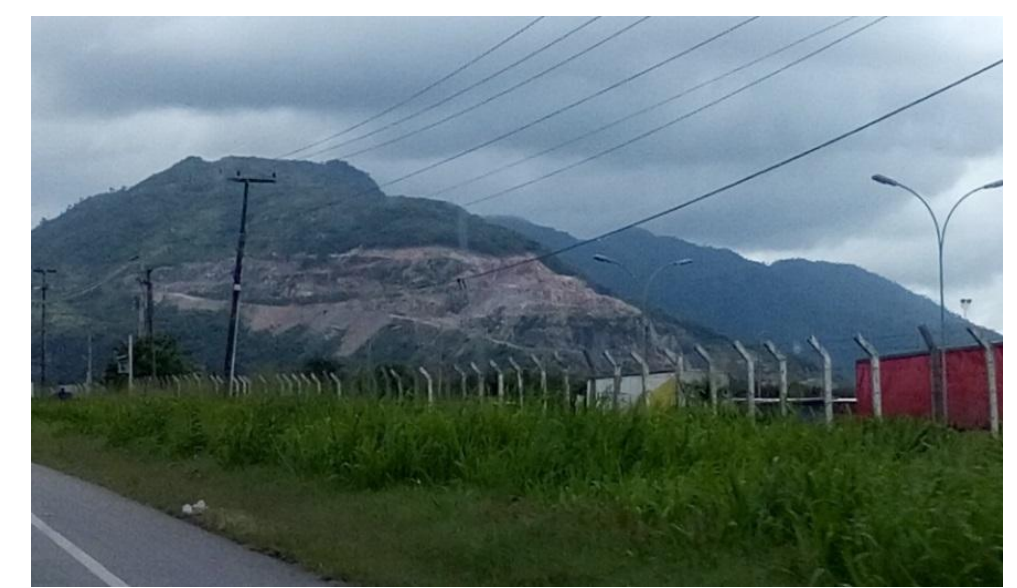

Figura 05. Encosta da Serra da Monguba desprotegida de vegetação. Fonte: BANDEIRA, 2016.

A retirada dos componentes naturais da área de estudo vem crescendo desde a implantação do Conjunto Industrial de Maracanaú (CAVALCANTI; PARAHYBA, 2011). No ano de 2001, segundo Cavalcanti e Parahyba (2011) a produção de brita na Região Metropolitana de Fortaleza era de 1 milhão de toneladas, no final de 2010 passou para 3 milhões de toneladas. Dessa forma, o setor produtor desse material aumenta a pressão 
exercida, além de trabalhar num limite próximo sua capacidade máxima e como consequência ocorre um aumento de áreas exploradas e de degradação, pois é necessária a retirada de vegetação e de solo para adquirir o granito que serve de matéria-prima para a produção de brita.

O impacto mais evidente na área de estudo é a modificação da paisagem causada pela atividade mineradora (Figura 05), pois se pode identificar vegetação de caatinga e de mata úmida bastante alterada devido ao desmonte do maciço, a qual influencia em processos de alteração da dinâmica dos solos, uma vez que, com a retirada da flora as chuvas atingem mais facilmente a superfície e levam as partículas existentes.

A sociedade é presente nesse sistema pertencente à natureza, pois as modificações antrópicas são capazes de alterar os processos naturais através de transformações na exploração biológica e que se reflete no potencial ecológico. Acarretando em modificações no relevo local. Segundo Casseti (1991), quando ocorre essa quebra de equilíbrio entre o potencial ecológico e a exploração biológica o ambiente caracteriza-se em resistasia prevalecendo os processos morfogenéticos. Caso a harmonia seja mantida se define em biostasia, o qual é propício os procedimentos pedogenéticos. Esse estado de equilíbrio da natureza é alterado pela evolução técnica obtida pelo homem. Desenvolvimento produto do conhecimento científico, a qual tem levado a sociedade explorar a natureza, atendendo diversas vezes os interesses capitalistas.

As mudanças ocorridas devido à atividade mineradora certamente influenciam no equilíbrio da área de estudo, uma vez que, a supressão da cobertura vegetal desprotege os solos que já são rasos e bastante pedregosos. Dessa forma, conforme Tricart (1977), devido ao dissecamento do relevo e da baixa capacidade protetora da vegetação, além da erosão dos solos originado pelo desmonte do Maciço. A área impactada pela atividade mineradora se apresenta com alto índice de vulnerabilidade há um risco ambiental e com condições instáveis, prevalecendo os processos morfogênicos em detrimento dos pedogênicos.

Essa ação socioeconômica quando não respeita o equilíbrio do sistema poderá acarretar em consequências desastrosas para a Serra da Monguba e sua população local, pois propicia o surgimento de conflitos entre os proprietários da pedreira e os moradores da área, além de acentuar a degradação. Esse processo quando analisado de forma sistêmica permite compreender a complexidade de suas relações e que de forma os impactos podem ser atenuados. 
Visto que a paisagem é o resultado das ações entre os processos que a compõem, ela passa a ser caracterizada por uma inter-relação entre o potencial ecológico a qual influencia no seu tipo de exploração biológica, inclusive aquela praticada pela sociedade. Esses procedimentos assumem traços essenciais que resultam em sua transformação. Dessa forma, a paisagem existe a partir de um processo de articulação entre os elementos constituintes do espaço (LIMA, 2013).

\section{CONCLUSÃO}

O presente trabalho abordou os elementos pertencentes à paisagem da área de estudo baseado na metodologia de Bertrand juntamente com a atuação da atividade mineradora na modificação de seus recursos. Foi possível identificar alteração nos componentes da exploração biológica a partir das ações socioeconômicas, consequentemente a dinâmica do ambiente é modificada comprometendo seu nível de equilíbrio local. Os dados obtidos a partir do trabalho de campo foram essenciais para entender essa mudança na paisagem, uma vez que, a supressão da cobertura vegetal e a retirada dos solos aumenta o índice de instabilidade do ambiente local, além de localizar-se em uma vertente.

Aliada a isso, a discussão ambiental a respeito da apropriação e exploração do relevo e seus reflexos, contribui para sabermos de que forma a ação socioeconômica vem agindo sobre a área. O estudo apontou indícios obtidos em trabalho de campo aliado a bibliografia citada, em relação às mudanças ocorridas na paisagem por meio a atividade mineradora. Além do mais, conclui-se que o desenvolvimento de técnicas de exploração dos elementos da natureza, contribui de maneira significante para acentuar os processos de degradação conciliando com a fragilidade local.

\section{REFERÊNCIAS}

BATISTA, C. T. A Mineração de Agregados na Região Metropolitana de Fortaleza: Impactos Ambientais e Conflitos de Uso e Ocupação do Solo. 2010. 147f. Dissertação (Mestrado em Geologia) - Universidade Federal do Ceará, Fortaleza, 2010.

BERTRAND, G. Paisagem e Geografia Física Global. Esboço Metodológico. Caderno de Ciências da Terra, São Paulo, n.13, 1972.

CAVALCANTI, Vanessa. M. M.; PARAHYBA, Ricardo Eudes R. A Indústria de Agregados para a Construção Civil na Região Metropolitana de Fortaleza. Fortaleza: DNPM, 2011.

CASSETI, V. Ambiente e apropriação do relevo. São Paulo: Contexto, 1991. 
EMBRAPA, Centro Nacional de Pesquisa de Solos. Sistema Brasileiro de classificação de solos. Rio de Janeiro: EMBRAPA-SPI, 2006.

LIMA, M. N. S. Classificação Ecodinâmica das Unidades de Paisagem na Área de Preservação Ambiental das Onças, no Município de São João do Tigre/PB. 2013. 134f. Dissertação (Mestrado em Geografia) - Universidade Federal da Paraíba, João Pessoa, 2013.

GUERRA, A. J. T; CUNHA, S. B. Geomorfologia e Meio Ambiente. Rio de Janeiro: Bertrand Brasil, 2006.

SOUZA, M. J. N. et al. Elaboração do Plano de Manejo da APA da Serra da Aratanha. 2007a.

SOUZA, M. J. N; OLIVEIRA, V. P. V. de. Os Enclaves Úmidos e Sub-Úmidos do SemiÁrido do Nordeste Brasileiro. Mercator, Fortaleza, ano 05, n. 09, 2006.

SOTCHAVA, V. B. O estudo de geossistemas. Instituto de Geografia. USP, São Paulo: Ed. Lunar, 1977.

TRICART, J. Ecodinâmica. Rio de Janeiro: IBGE, 1977.

\section{AGRADECIMENTOS}

À Deus, primeiramente, por estar sempre comigo e me guiando. A Universidade Estadual do Ceará - UECE, pela disponibilidade do auxílio financeiro para o Simpósio e o apoio institucional. A Pró-Reitoria de Políticas Estudantil, por destinar uma bolsa de permanência universitária. Ao Laboratório de Geoprocessamento e Estudos Aplicados, devido ao desimpedimento de ceder artigos, livros e computadores para a realização do trabalho. A Biblioteca Central da UECE, pelo acervo de materiais disponibilizados para a produção da obra. A Embrapa e ao Departamento Nacional de Produção Mineral através das informações viabilizadas. E a todos que ajudaram nesse trabalho. Obrigado!

Recebido em: 14/08/2016

Aceito para publicação em: 01/10/2016 